\title{
Investigating the effect of knowledge management on human resources productivity
}

\author{
Hadi Khodaee $^{a^{*}}$, Valiallah Omrani ${ }^{\mathrm{b}}$, Hojjat Kazemi ${ }^{\mathrm{b}}$, Iraj Jabari Tamar ${ }^{\mathrm{c}}$ and Allahyar Piri ${ }^{\mathrm{d}}$
}

${ }^{a}$ Ph.d Department of Management, Shahindegh Branch, Islamic Azad University, Shahindegh, Iran

${ }^{b}$ MA student Department of Management, Bonab Branch, Islamic Azad University, Bonab, Iran

${ }^{c} \mathrm{MA}$ of public management. Iran İansurance. Co

${ }^{d}$ Ph.d student, Department of Management, Payame Noor University, PO BOX 19395-3697 Tehran, Iran

\section{CH R O N I C L E}

Article history:

Received October 28, 2015

Received in revised format

November 28, 2015

Accepted January 28, 2016

Available online

February 2, 2016

Keywords:

Knowledge and social

management

Externalization

Combination

Internalization of organizational

knowledge in organizations

Productivity

\begin{abstract}
A B S T R A C T
The objective of the present study is to investigate the effect of knowledge management on the productivity of the staff working at Islamic Azad University, Bonab Branch. The study uses knowledge management based on Nonaka and Takeuchi's theory in four cases of socialization, externalization, combination and internalization of social knowledge. The population of the present study includes all 89 staff working at Islamic Azad University. Regarding the small number of the population, the whole population was selected as the sample, i.e. the census method was used. After collecting questionnaires, the obtained information were summarize and categorized using descriptive statistics and to test research hypotheses, bivariate regression was used. The present study employs a survey research for collecting data and it is an applied research in terms of objective. The results indicate that knowledge management and its dimensions are effective on the productivity of the staff working at Islamic Azad University.
\end{abstract}

(C) 2016 Growing Science Ltd. All rights reserved.

\section{Introduction}

During the past two decades, knowledge and information are considered as the most important resources of creating value and the most important factors for creating competitive advantage, as a results, they have been changed into necessary activities. The expansion of advanced technologies, rapid communication systems, rapid access to the internet and globalization of some of changes have forced organizations to concentrate doubly on management of intellectual capitals and knowledge properties. The necessity of the management of processes related to knowledge, time, and capital spent for these activities have made the evaluation of the performance necessary. Performance evaluation provides suitable information for planning objectives and future activities as well as the evaluation of the advancement of these activities for organizations. Knowledge management can be defied as the 
processes of effective learning along with creating, organizing, and exchanging knowledge. This includes implicit and explicit knowledge which with appropriate use of technology as instrument and cultural environment are realized.

Nowadays, competitive advantage of organizations on human resources has been recognized. One of these methods is operationalizing and applying the principles of knowledge management in organizations. Challenges facing knowledge management are as follows: most of managers face different challenges in understanding practical aspects of knowledge management. These challenges have occurred because traditional managers were involved mostly in physical and tangible resources. The biggest challenge facing the success of knowledge management in organizations is the quiddity of production, transformation, and transference of organizational knowledge. This challenge are mostly resulted from challenges of management control, economic productivity, and organizational structure.

\subsection{Knowledge management and its significant}

Knowledge management, which can produce the power of compatibility and survival for organizations, is based on the attraction and productivity of knowledge and its management. But, for organizations which are to be responsible in the today's developing information world and have competitive positions, it is vital to experience the access to processes of knowledge management, practically. According to Drucker (2008), we are entering a knowledge community in which the main economic resources are no longer considered as capitals, natural resources, or working, but it is knowledge and knowledge-based staff which have main functions. During the $19^{\text {th }}$ century, economists discussed the differences in workers' skills and argued low level and high level skills as well as productive and nonproductive workers. However, Taylor directly did not referred to the issue of skill, he paid attention to the issue of scientific methodology of doing work.

Yang (2010) investigated the effect of knowledge management strategy on strategic performance in Chinese High Technology organizations. Yang reported that the knowledge management strategyperformance connection was contingent on both performance-driven strategies, including reward system and process innovation and knowledge management-based competencies. Darroch (2003) presented a scale developed to measure knowledge management behaviors and practices. Lee and Choi (2003) studied knowledge management enablers, processes, and organizational performance by developing a framework, which interconnects knowledge management factors. The focus was on knowledge creation processes such as socialization, externalization, combination, and internalization and confirmed the effect of trust on knowledge creation. The information technology support, in their survey, maintained a positive effect only on knowledge combination while organizational creativity was detected to be essential for improving performance.

Tippins and Sohi (2003) tried to find out whether organization learning plays an essential role in detecting the outcomes of information technology (IT) and through an empirical survey detected that organizational learning indeed plays a substantial role in mediating the impacts of IT competency on firm performance. Kalling (2003) argued that current research into knowledge management could fail to offer an insight about the role of knowledge in improving firm performance. Instead of concentrating on the nature of knowledge, and the management of learning, studies ought to direct more attention to the factors that enable knowledge to contribute to performance. They reported that the concept of knowledge management could be divided into three instances; development, utilization and capitalization, according to the assumption that knowledge is not always utilized. The study also identified challenges and solutions in association with each of the instances. Zack et al. (2009) reported the results of an exploratory study of the organizational effect of knowledge management (KM) and reported that KM practices directly associated with organizational performance which, in turn, was also directly associated with financial performance. However, there seemed to be no direct relationship between KM practices and financial performance. 


\section{The proposed study}

The main objective of the present study is to investigate the effect of knowledge management on the productivity of the staff working at Islamic Azad University, Bonab Branch. Accordingly, the secondary objectives are as follows:

1. To investigate and determine the degree of effectiveness of the dimension of socialization of organizational knowledge on the productivity of the staff working at Islamic Azad University, Bonab Branch.

2. To investigate and determine the degree of effectiveness of the dimension of externalization of organizational knowledge on the productivity of the staff working at Islamic Azad University, Bonab Branch.

3. To investigate and determine the degree of effectiveness of the dimension of combination of organizational knowledge on the productivity of the staff working at Islamic Azad University, Bonab Branch.

4. To investigate and determine the degree of effectiveness of the dimension of internalization of organizational knowledge on the productivity of the staff working at Islamic Azad University, Bonab Branch.

In this paper, we have investigated the effect of knowledge management on the productivity of the staff working at Islamic Azad University, Bonab Branch. The study has applied knowledge management based on Nonaka and Takeuchi's theory (Nonaka \& Takeuchi, 1995) in four cases of socialization, externalization, combination and internalization of social knowledge. The population of the present study includes all 89 staff working at Islamic Azad University. Regarding the small number of the population, the whole population was selected as the sample, i.e. the census method was used.

To analyze data obtained from questionnaires, descriptive and inferential statistics have been used. Accordingly, to describe the answers to the questions of the questionnaire, frequency distribution and percentage tables of the answers related to each question have been used. To indicate the statistical data of the general questions in an integrated way, column charts have been used and at the inferential level, to test hypotheses, bivariate regression was used.

\subsection{The main hypothesis}

The first hypothesis of this study investigate whether or not knowledge management is effective on the productivity of the staff working at Islamic Azad University of Bonab.

$\mathrm{H}_{0}$ : Knowledge management is effective on the productivity of the staff working in Islamic Azad University of Bonab.

$\mathrm{H}_{1}$ : Knowledge management is not effective on the productivity of the staff working in Islamic Azad University of Bonab.

To measure the impact of the effectiveness of knowledge management $(x)$ on staff productivity $(y)$, the following regression analysis has been executed.

$$
y=\beta_{0}+\beta_{1 x}+\varepsilon
$$

where $\beta_{0}$ and $\beta_{1}$ are intercept and slope, respectively and $\varepsilon$ represents residuals. The results of regression estimate are summarized as follows,

$$
\begin{array}{lcc} 
& \mathrm{y}=5.941+0.987 \mathrm{x}_{1} \\
\text { t-value } & 1.355 & 16.315 \\
\text { Sig. } & (0.000) & (0.000) \\
\text { F-value }=266.156(0.000) & \text { Adjusted R-Square }=0.754
\end{array}
$$


As indicated in Eq. (2), the significant level of the test is 0.000 and it can be claimed that the mentioned test at the error level 0.05 or significant level 0.95 is meaningful. Therefore, $\mathrm{H}_{1}$ is confirmed and $\mathrm{H}_{0}$ is rejected. Regarding the $\mathrm{R}^{2}$ indicating the ratio of variations explained by variable $x$ to total variations, is 0.754 . It can be claimed that $75.4 \%$ of variations of the staff productivity can be explained by the variations in their knowledge management. Therefore, it can be concluded that a unit increase in the independent variable of knowledge management causes 0.987 unit increase on the employees' productivity of Islamic Azad University.

\subsubsection{The first sub-hypothesis}

The socialization dimension of Knowledge management is effective on the productivity of the staff working at Islamic Azad University of Bonab.

$\mathrm{H}_{0}$ : The socialization dimension of knowledge management is effective on the productivity of the staff working at Islamic Azad University of Bonab.

$\mathrm{H}_{1}$ : The socialization dimension of knowledge management is not effective on the productivity of the staff working at Islamic Azad University of Bonab.

To measure the impact of the effect of socialization dimension of knowledge management $(x)$ on staff productivity $(y)$, the following regression analysis has been executed.

$$
\begin{array}{lcc} 
& \mathrm{y}=21.051+2.992 \mathrm{x}_{1} \\
\text { t-value } & 4.216 & 11.300 \\
\text { Sig. } & (0.000) & (0.000) \\
\text { F-value }=127.697(0.000) & \text { Adjusted R-Square }=0.590
\end{array}
$$

As indicated Eq. (3), the significant level of the test is 0.000 and it can be claimed that the mentioned test at the error level 0.05 or significant level 0.95 is significant. Therefore, $\mathrm{H}_{1}$ is confirmed and $\mathrm{H}_{0}$ is rejected. Regarding the $\mathrm{R}^{2}$ indicating the ratio of variations explained by variable $x$ to total variations, is 0.595 . It can be claimed that $59.5 \%$ of variations of the staff productivity can be explained by the variations in the socialization dimension of knowledge management. Therefore, the first sub-hypothesis is confirmed.

\subsubsection{The second sub-hypothesis}

The externalization dimension of Knowledge management is effective on the productivity of the staff working at Islamic Azad University of Bonab.

$\mathrm{H}_{0}$ : The externalization dimension of knowledge management is effective on the productivity of the staff working at Islamic Azad University of Bonab.

$\mathrm{H}_{1}$ : The externalization dimension of knowledge management is not effective on the productivity of the staff working at Islamic Azad University of Bonab.

To measure the impact of the effect of externalization dimension of knowledge management $(x)$ on staff productivity $(y)$, the following regression analysis has been executed.

$$
\begin{array}{lcc} 
& \mathrm{y}=26.178+2.849 \mathrm{x}_{1} \\
\text { t-value } & 5.115 & 10.018 \\
\text { Sig. } & (0.000) & (0.000) \\
\text { F-value }=127.697(0.000) & \text { Adjusted R-Square }=0.530
\end{array}
$$

As indicated in Eq. (4), the significant level of the test is 0.000 and it can be claimed that the mentioned test at the error level 0.05 or significant level 0.95 is significant. Therefore, $\mathrm{H}_{1}$ is confirmed and $\mathrm{H}_{0}$ is rejected. Regarding the $\mathrm{R}^{2}$ indicating the ratio of variations explained by variable $x$ to total variations, is 0.536 . It can be claimed that $53.6 \%$ of variations of the staff productivity can be explained by the 
variations in the externalization dimension of knowledge management. Therefore, it can be concluded that a unit increase in the independent variable of the externalization dimension of knowledge management causes 2.849 unit increase in the staff productivity of Islamic Azad University.

\subsubsection{The third sub-hypothesis}

The combination dimension of Knowledge management is effective on the productivity of the staff working at Islamic Azad University of Bonab.

$\mathrm{H}_{0}$ : The combination dimension of knowledge management is effective on the productivity of the staff working at Islamic Azad University of Bonab.

$\mathrm{H}_{1}$ : The combination dimension of knowledge management is not effective on the productivity of the staff working at Islamic Azad University of Bonab.

To measure the impact of the effect of combination dimension of knowledge management $(x)$ on staff productivity $(y)$, the following regression analysis has been executed.

$$
\begin{array}{lc} 
& \mathrm{y}=16.046+3.221 \mathrm{x}_{1} \\
\text { t-value } & 3.098511 .834 \\
\text { Sig. } & (0.000)(0.000) \\
\text { F-value }=140.052(0.000) & \text { Adjusted R-Square }=0.612
\end{array}
$$

As indicated in Eq. (5), the significant level of the test is 0.000 and it can be claimed that the mentioned test at the error level 0.05 or significant level 0.95 is significant. Therefore, $\mathrm{H}_{1}$ is confirmed and $\mathrm{H} 0$ is rejected. Regarding the $\mathrm{R}_{2}$ indicating the ratio of variations explained by variable $x$ to total variations, is 0.617 . It can be claimed that $61.7 \%$ of variations of the staff productivity can be explained by the variations in the combination dimension of knowledge management. Therefore, it can be concluded that a unit increase in the independent variable of the combination dimension of knowledge management causes 3.221 unit increase in the staff productivity of Islamic Azad University.

\subsubsection{The fourth hypothesis}

The internalization dimension of Knowledge management is effective on the productivity of the staff working at Islamic Azad University of Bonab.

$\mathrm{H}_{0}$ : The internalization dimension of knowledge management is effective on the productivity of the staff working at Islamic Azad University of Bonab.

$\mathrm{H}_{1}$ : The internalization dimension of knowledge management is not effective on the productivity of the staff working at Islamic Azad University of Bonab.

To measure the impact of the effect of internalization dimension of knowledge management $(x)$ on staff productivity $(y)$, the following regression analysis has been executed.

$$
\begin{array}{lcc} 
& \mathrm{y}=11.696+3.827 \mathrm{x}_{1} \\
\text { t-value } & 2.590 & 14.576 \\
\text { Sig. } & (0.000) & (0.000) \\
\text { F-value }=212.449(0.000) & \text { Adjusted R-Square }=0.706
\end{array}
$$

As indicated in Eq. (6), the significant level of the test is 0.000 and it can be claimed that the mentioned test at the error level 0.05 or significant level 0.95 is significant. Therefore, $\mathrm{H}_{1}$ is confirmed and $\mathrm{H} 0$ is rejected. Regarding the $\mathrm{R}_{2}$ indicating the ratio of variations explained by variable $x$ to total variations, is 0.709 . It can be claimed that $70.9 \%$ of variations of the staff productivity can be explained by the variations in the internalization dimension of knowledge management. Therefore, it can be concluded that a unit increase in the independent variable of the internalization dimension of knowledge management causes 3.221 unit increase in the staff productivity of Islamic Azad University. 


\section{Discussion and conclusion}

In this paper, we have investigated the effect of knowledge management on the productivity of the staff working at Islamic Azad University, Bonab Branch. The study has applied knowledge management based on Nonaka and Takeuchi's theory in four cases of socialization, externalization, combination and internalization of social knowledge. The population of the present study includes all 89 staff working at Islamic Azad University. Regarding the small number of the population, the whole population was selected as the sample, i.e. the census method was used. After collecting questionnaires, the obtained information were summarize and categorized using descriptive statistics and to test research hypotheses, bivariate regression was used. The present study has employed a survey research for collecting data and it is an applied research in terms of objective. The results have indicated that knowledge management and its dimensions were effective on the productivity of the staff working at Islamic Azad University.

The results of the present study have indicated that the highness of knowledge management causes the enhancement of the level of the staff productivity. Therefore, exerting efforts for increasing knowledge management results in the productivity of the staff and this issue provides the ground for enhancing the level of the productivity of the staff at Islamic Azad University of Bonab. Therefore, it is suggested that policymakers consider the following issues for enhancing and reinforcing knowledge management and the staff productivity.

1. Strengthening the management of knowledge,

2. Strengthening the knowledge society,

3. Strengthening the external organizational knowledge,

4. Strengthening the bond and connection to organizational knowledge.

\section{Acknowledgement}

The authors would like to thank the anonymous referees for constructive comments on earlier version of this work.

\section{References}

Darroch, J. (2003). Developing a measure of knowledge management behaviors and practices. Journal of knowledge management, 7(5), 41-54.

Drucker, P. F. (2008). Management Rev Ed. Zondervan.

Kalling, T. (2003). Knowledge management and the occasional links with performance. Journal of knowledge management, 7(3), 67-81.

Lee, H., \& Choi, B. (2003). Knowledge management enablers, processes, and organizational performance: An integrative view and empirical examination. Journal of management information systems, 20(1), 179-228.

Nonaka, I., \& Takeuchi, H. (1995). The knowledge-creating company: How Japanese companies create the dynamics of innovation. Oxford university press.

Tippins, M. J., \& Sohi, R. S. (2003). IT competency and firm performance: is organizational learning a missing link?. Strategic Management Journal, 24(8), 745-761.

Yang, J. (2010). The knowledge management strategy and its effect on firm performance: A contingency analysis. International Journal of Production Economics, 125(2), 215-223.

Zack, M., McKeen, J., \& Singh, S. (2009). Knowledge management and organizational performance: an exploratory analysis. Journal of knowledge management, 13(6), 392-409.

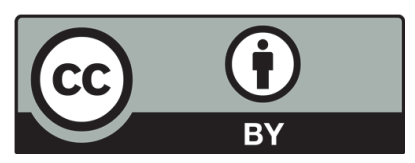

(C) 2016 by the authors; licensee Growing Science, Canada. This article is an open access article distributed under the terms and conditions of the Creative Commons Attribution (CC-BY) license (http://creativecommons.org/licenses/by/4.0/). 